\title{
Development of a Dual-Fuel Gas Turbine Engine of Liquid and Low-Calorific Gas*
}

\author{
Masamichi KOYAMA** and Hiroshi FUJIWARA**
}

\begin{abstract}
We developed a dual-fuel single can combustor for the Niigata Gas Turbine (NGT2BC), which was developed as a continuous-duty gas turbine capable of burning both kerosene and digester gas. The output of the NGT2BC is $920 \mathrm{~kW}$ for continuous use with digester gas and $1375 \mathrm{~kW}$ for emergency use with liquid fuel. Digester gas, obtained from sludge processing at sewage treatment plants, is a biomass energy resource whose use reduces $\mathrm{CO}_{2}$ emissions and take advantage of an otherwise wasted energy source. Design features for good combustion with digester gas include optimized the good matching of gas injection and swirl air and reduced reference velocity. The optimal combination of these parameters was determined through CFD analysis and atmospheric rig testing.
\end{abstract}

Key Words: Dual-Fuel, Digester Gas, Combustor, Gas Turbine (Niigata Gas Turbine NGT2BC)

\section{Introduction}

As exemplified by use of digester gas generated during anaerobic digestion of sewage sludge, low-calorie gases are seeing growing use as biomass fuel in efforts to reduce $\mathrm{CO}_{2}$ emissions and make efficient use of previously untapped energy sources. While over 1000 sewage treatment plants operate in Japan, only 20 or so large-scale plants located in major cities use power generation for energy recovery. Most such facilities provide power on the order of several hundred $\mathrm{kW}$, based on gas engine power generation systems. No digester gas power generation in Japan involves gas turbines in the $1000 \mathrm{~kW}$ class. Since sewage treatment plants account for approximately $0.6 \%$ of total national electricity consumption, generating power from sewage sludge digester gas offers a potential route toward increased energy self-sufficiency.

This paper describes the development of a $1000 \mathrm{~kW}$ gas turbine engine capable of burning either kerosene or low-calorie gas with a heat value of $21 \mathrm{MJ} / \mathrm{Nm}^{3}$ or less, at high combustion efficiency.

\section{Digester Gas Cogeneration}

Figure 1 is a flowchart of a digester gas cogeneration system in a sewage treatment plant. Digester gas is gen-

* Received 28th September, 2005 (No. 05-4178)

** Niigata Power Systems Co., Ltd., 2756-3 Higashiko 5Chome, Seirou-Machi, Kitakanbara-Gun, Niigata 9570101, Japan. E-mail: koyamama@ niigata-power.com

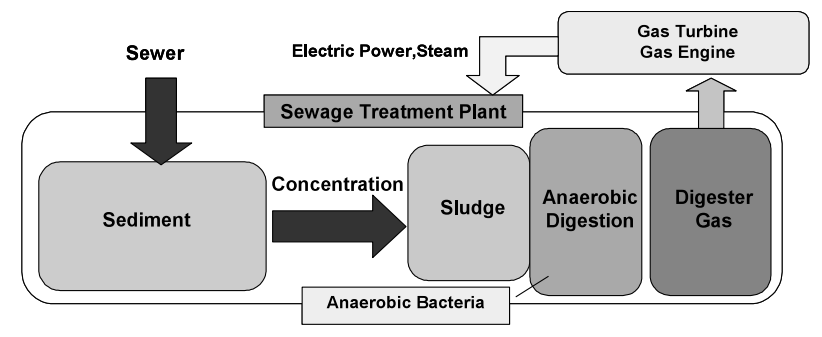

Fig. 1 Flow chart of digester gas cogeneration

erated during anaerobic digestion of sewage sludge. The digester gas is supplied as fuel for a gas turbine or gas engine. The electric power and steam heat are returned to the sewage treatment plant. Effective use of unused fuel has several benefits, including energy conservation and lower $\mathrm{CO}_{2}$ emissions.

\section{Sludge Digester Gas Characteristics}

The following four characteristics are primarily responsible for degrading the combustion characteristics of sludge digester gas. First, the calorific value of digester gas is approximately half that of town gas, requiring major modifications to gas feed systems to handle the necessary increases in gas volumes. Second, digester gas has a high specific gravity-approximately 1.0. The higher resulting increased gas momentum requires an appropriate gas injection method. Third, the burning velocity of digester gas is approximately half that of town gas, reducing flame stability. Finally, the inert gas content of digester gas reduces flame temperatures in the combustion 
Table 1 Basic specification of the digester gas

\begin{tabular}{|l|c|c|c|c|c|c|c|}
\hline \multicolumn{1}{|c|}{ Vol \% } & $\mathrm{H}_{2}$ & $\mathrm{CO}$ & $\mathrm{CH}_{4}$ & $\mathrm{C}_{2} \mathrm{H}_{6}$ & $\mathrm{C}_{3} \mathrm{H}_{8}$ & $\mathrm{C}_{4} \mathrm{H}_{10}$ & $\mathrm{~N}_{2}$ \\
\hline Town gas & - & - & 88.5 & 4.6 & 5.4 & 1.5 & - \\
\hline Digester gas & 0.05 & 0.1 & 57.9 & - & - & - & 1.2 \\
\hline \hline Vol \% & $\mathrm{O}_{2}$ & $\mathrm{CO}_{2}$ & $\mathrm{H}_{2} 0$ & $\mathrm{BV}$ & $\mathrm{SG}$ & $\mathrm{LHV}$ \\
\hline Town gas & - & - & - & 40.12 & 0.65 & 41.61 \\
\hline Digester gas & 0.3 & 37.8 & 2.8 & 19.98 & 0.94 & 21.58 \\
\hline
\end{tabular}

BV : Burning Velocity $(\mathrm{cm} / \mathrm{s})$

SG : Specific Gravity $\left(\mathrm{Nm}^{3} / \mathrm{Nm}^{3}\right)$

LHV : Low Heat Value $\left(\mathrm{MJ} / \mathrm{Nm}^{3}\right)$

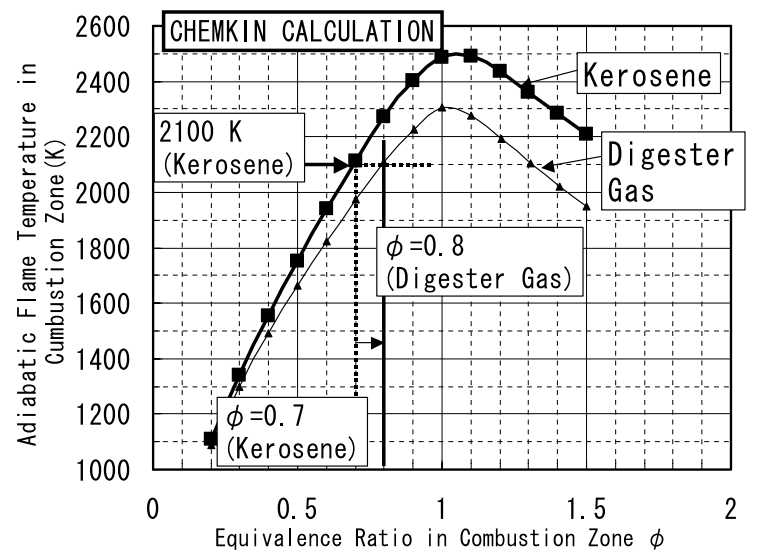

Fig. 2 CHEMKIN calculation results of flame temperature

zone. Table 1 gives the basic specifications for town gas and digester gas. Figure 2 shows equilibrium adiabatic flame temperatures in the combustion zone for kerosene and digester gas. Adiabatic flame temperature was calculated to equilibrium using CHEMKIN software. Thermodynamic data and chemical reaction data were defined by GRI-Mech 3.0. For combustion zone equivalence ratios, adiabatic flame temperatures would be $150^{\circ} \mathrm{C}$ lower for digester gas than for kerosene. With digester gas combustion, we must therefore increase the combustion zone equivalence ratio by reducing the amount of air introduced into the combustion zone.

\section{Gas Turbine Engine}

The base engine is the NGT2BC, a $1500 \mathrm{~kW}$ class gas turbine designed for continuous use. The engine power was derated for continuous operations at $920 \mathrm{kWe}$ with digester gas fuel and at $1375 \mathrm{kWe}$ with kerosene in emergencies. The NGT2BC can also burn both town gas and kerosene. Figure 3 shows a cross-sectional diagram of the gas turbine engine. Figure 4 illustrates the combustor design.

\section{Development Overview}

The development work consisted of preliminary studies using CFD (Computational Fluid Dynamics), atmospheric pressure combustion testing, and engine testing. Digester gas was simulated using a mixture of town gas $(13 \mathrm{~A})$ and $\mathrm{CO}_{2}$ to create a low calorific value of around

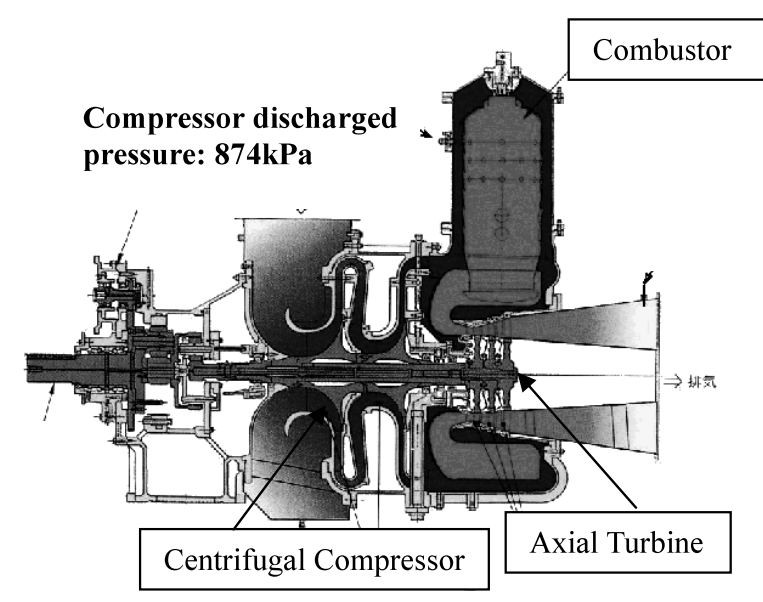

Fig. 3 Cross sectional view of NGT2BC

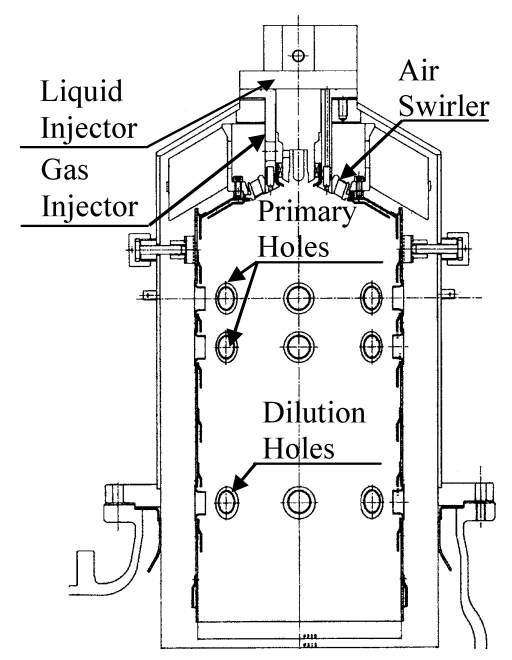

Fig. 4 Base combustor liner

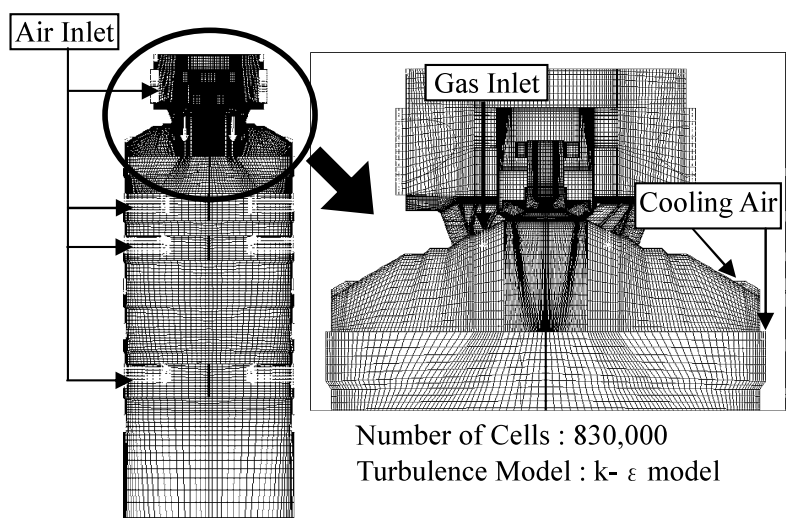

Fig. 5 CFD model

$18 \mathrm{MJ} / \mathrm{Nm}^{3}$. The two main development features are described below.

\subsection{Fuel gas injection method and air swirler matching}

We applied CFD analysis to identify the optimum gas injection method for fuel-air mixtures. The CFD model is shown in Fig. 5. Velocity conditions were defined at the 


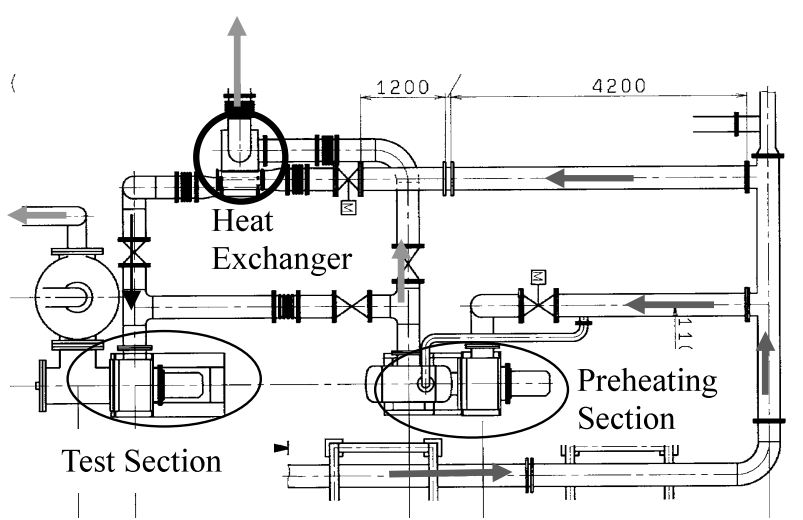

Fig. 6 Combustion test rig

Table 2 Combustion test condition

\begin{tabular}{|l|c|c|}
\hline Combustor Inlet Temperature & $\mathrm{K}$ & 593 \\
\hline Air Flow Rate & $\mathrm{Kg} / \mathrm{s}$ & 1.0 \\
\hline Air Pressure & $\mathrm{kPa}$ & 101.3 \\
\hline Fuel Flow Rate & $\mathrm{Nm}^{3}$ or $\mathrm{L} / \mathrm{h}$ & Variable \\
\hline
\end{tabular}

air and gas inlets. Inlet conditions for gas injection were simulated by a tangential component. Combustion tests were performed by three gas swirl injection methods and air swirlers to identify the combination providing optimal combustion efficiency and flame stability.

\subsection{Increasing residence time}

Since digester gas involves lower burning velocity, we increased the residence time inside the combustor by increasing the combustor diameter at combustion zone.

\section{Atmospheric Pressure Combustion Test Rig}

Figure 6 is a schematic diagram of the combustion test rig. The air discharged from the electric blower is divided for use in preheating and in the test section. Air for combustion is preheated in a heat exchanger before being supplied to the test section. Exhaust gas is water-cooled in the cooling tower before release into the atmosphere. Sampling probes located at the test section outlet measure $\mathrm{NOx}, \mathrm{CO}, \mathrm{CO}_{2}, \mathrm{O}_{2}$, and THC components in the combustion gas. Table 2 gives the combustion test conditions.

\section{Examination and Test Results}

\subsection{Gas injection method}

We tested three gas injections. One was a straight configuration with no swirl component. The two others imparted swirl, one in the same direction as the air swirler swirl and the other in the opposite, as shown in Fig. 7. Figure 8 shows the fuel gas concentration CFD results and combustion test flame conditions for the three gas injection directions.

The CFD results for the straight injection configuration showed a region with extremely high fuel concentrations at the center of the liner. In the combustion test, the resulting flame was dim and unstable. With forward

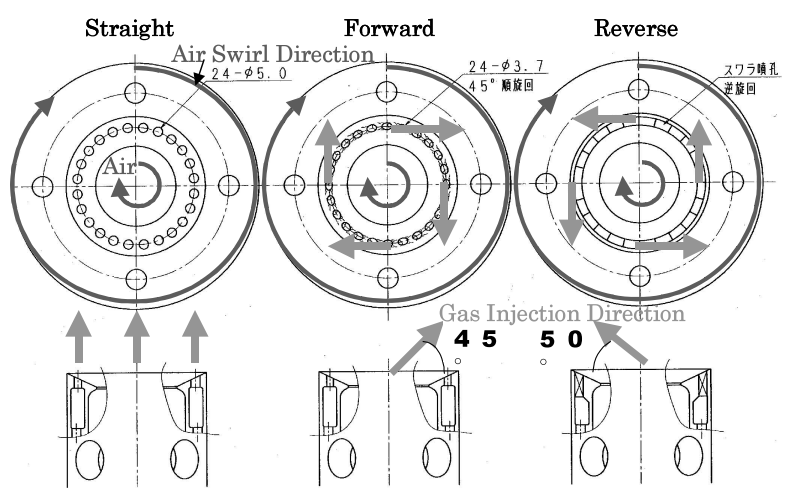

Fig. 7 Gas injection methods

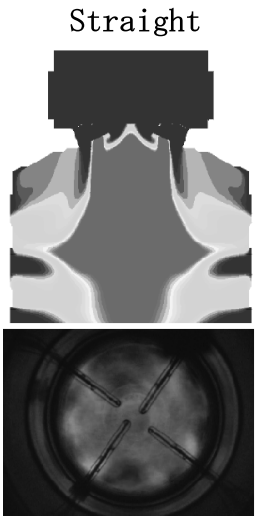

$\phi=0.16$

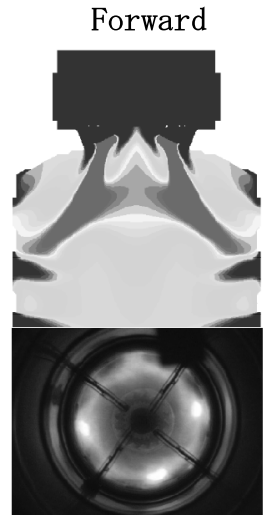

$\phi=0.15$

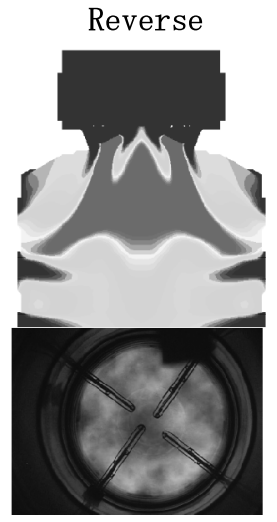

$\phi=0.15$
Fig. 8 Gas fuel concentration CFD results and combustion test flame conditions

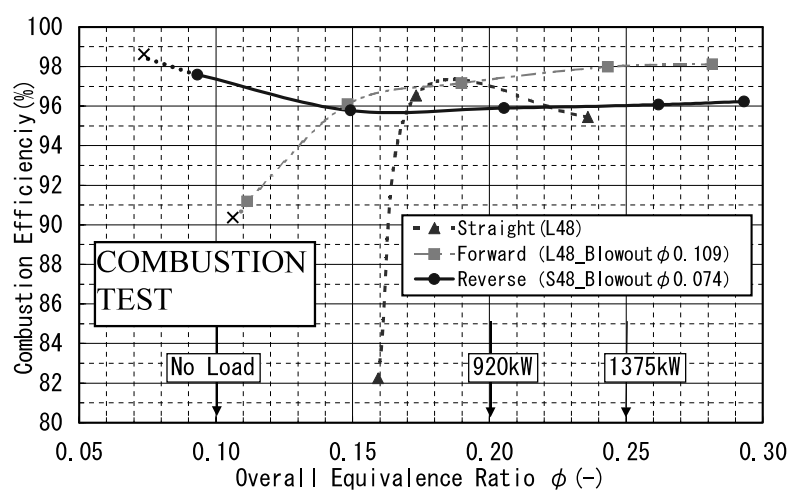

Fig. 9 Combustion efficiencies of the combustion

swirl injection, fuel tended to concentrate at the periphery of the liner, where the flame was also brighter. But with reverse swirl injection, fuel spread evenly throughout the liner, and the flame was both bright and stable, indicating good fuel-air mixing.

Figure 9 shows the combustion efficiencies for digester gas combustion in the combustion tests. The combustion efficiencies show clear differences among the three injection methods. For straight injection, flame stability is poor in the low-load region, while rig combustion efficiency drops rapidly from around the point at which 


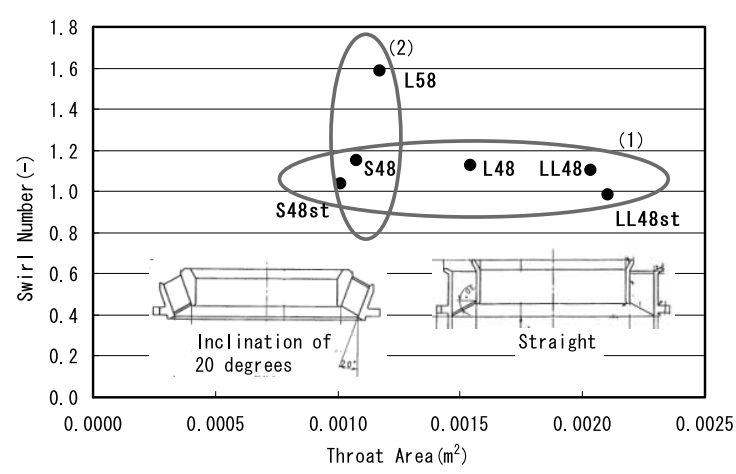

Fig. 10 Swirl numbers and throat areas of tested swirler

overall equivalence ratio $\phi$ is near 0.17. A comparison of forward and reverse swirl injection shows higher efficiency for reverse swirl in the low-load region, with the blowout limit (marked " $x$ ") shifted towards the low-load region. Since these results indicate that the straight injection method is unsuitable for digester gas, only the forward and reverse swirl injection methods were used in subsequent testing.

\subsection{Gas injection method and swirler matching}

Digester gas injection methods that impart a swirl component, either forward or reverse, achieved stable combustion of digester gas.

Combustion tests were performed with these injection methods to identify swirler combination with the highest combustion efficiency.

Different swirlers were tested with differing throat areas and swirl numbers. Figure 10 shows the correlation between throat area and swirl number. The S, L, and LL notations for the swirlers indicate the throat area. "st" indicates straight in the axial direction, and figures indicate the swirl angle. Those not marked with "st" are turned in by 20 degrees. Testing was performed by fixing the swirl number and varying throat area (1), and by fixing the throat area and varying swirl number (2).

Figure 11 shows the results for fixed swirl number and varying throat areas. Figure 12 shows the results for fixed throat area and varying swirl numbers. Figure 11 shows that combustion efficiency increases with throat area for both forward and reverse swirl injection. But for reverse swirl injection, efficiency drops off rapidly towards diluted sides with large throat areas. Figure 12 shows that combustion efficiency increases with swirl numbers for forward swirl injection and decreases with swirl numbers for reverse swirl injection. We observed blowout for reverse swirl injection for lower equivalence ratios than for forward swirl injection. Reverse swirl injection gave better flame stability in low load regions.

These results show that certain combinations of gas injection method and air swirler improve efficiency and blowout characteristics. For reverse swirl injection, a large throat area and small numbers of swirls increase combus-

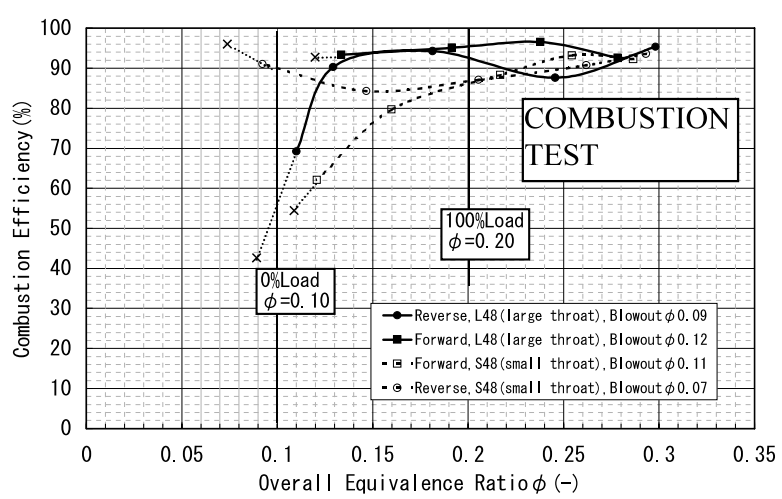

Fig. 11 Combustion efficiencies (Varying the throat area)

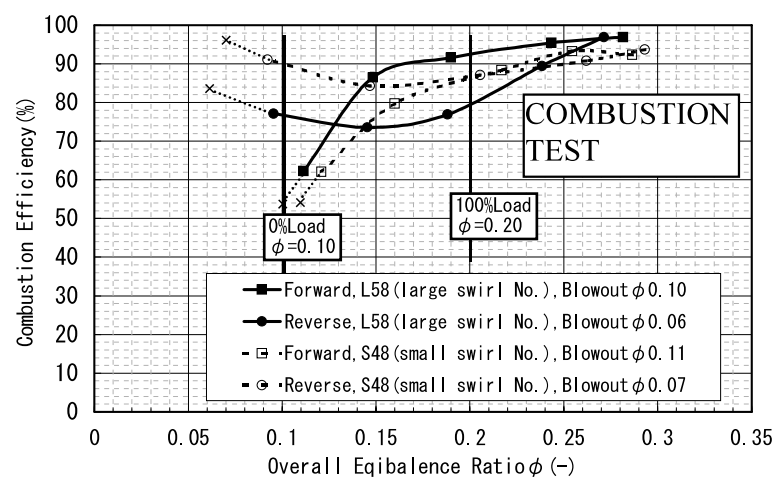

Fig. 12 Combustion efficiencies (Varying the swirl number)

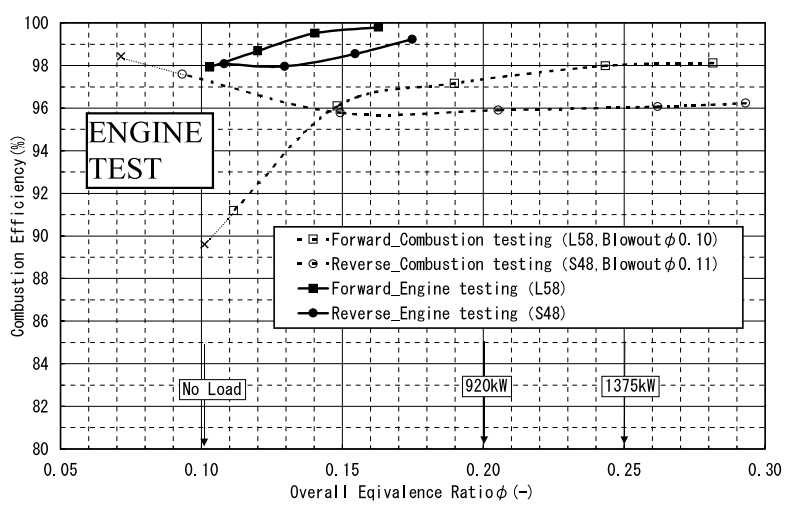

Fig. 13 Results of initial in engine testing

tion efficiency and flame stability at low loads, while for forward swirl injection, optimal results are achieved with large throat areas and small numbers of swirls.

In initial engine testing, the L58 swirler was used with forward swirl injection, while the S48 swirler was used with reverse swirl injection.

\subsection{Initial engine testing}

Figure 13 shows the results of initial engine testing. The heavy lines indicate engine test results, while dotted lines indicate corresponding combustion test results. Both lines show remarkably similar trends. The engine tests show higher overall combustion efficiencies than combustion tests due to the increased effects of combustion reaction under high pressure. Both forward and reverse 


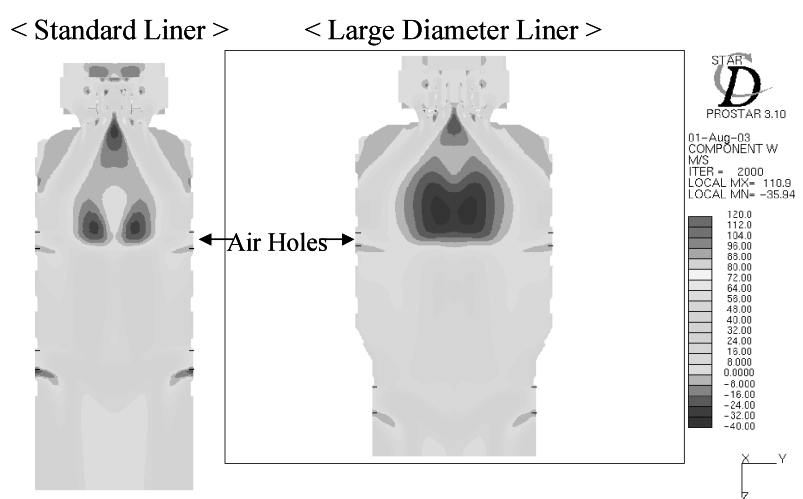

Fig. 14 Axial velocity distributions of CFD

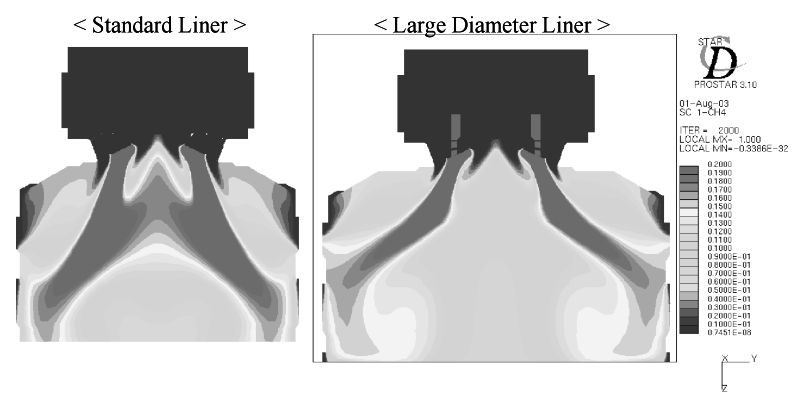

Fig. 15 Gas fuel concentration distributions of CFD

swirl injection showed high combustion efficiencies from the mid-load region upward, but efficiencies dropped to around $98 \%$ for no load. To counter this drop in combustion efficiency, we increased residence time within the combustor by increasing liner diameter.

\subsection{Increasing residence time}

We applied CFD analysis to investigate the effects of reference velocity on combustor performance. The results are shown in Figs. 14 and 15 as axial velocity and fuel concentration distributions. We used reverse swirl fuel injection, since this method gave good flame stability in the low-load region.

For axial velocity distribution, the dark areas indicating reverse flow appear to expand with increased liner diameter. That is, combustors with greater liner diameters should allow longer residence times than standard diameters. Axial velocities downstream from the air holes are also reduced overall, which is better for digester gas combustion.

For large diameter liners, fuel concentration distributions are evenly distributed over the larger area. This suggests that large diameter liners will provide slower, more uniform combustion than standard diameter liners.

Figure 16 shows the results of combustion tests to identify the effects of increasing liner diameter on combustor performance. Simply increasing liner diameter while maintaining a constant combustion zone air increased combustion efficiency by approximately $3 \%$.

\subsection{Engine testing with large diameter liners}

Figure 17 shows the test results. In combustors with

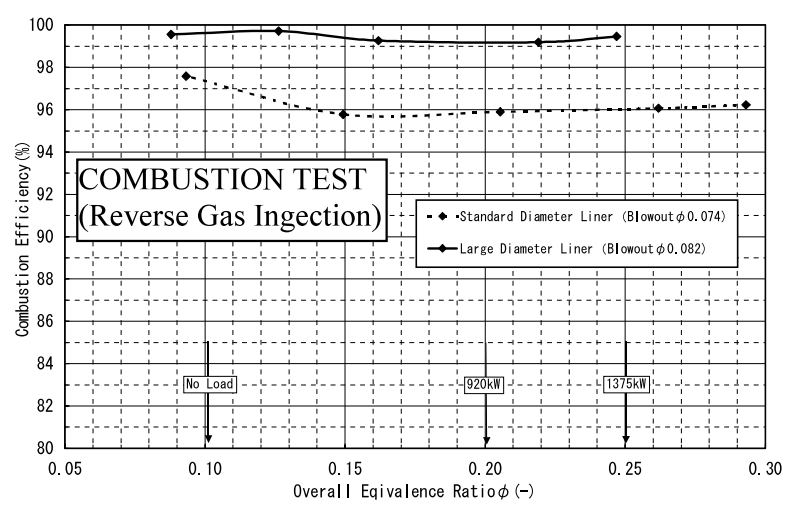

Fig. 16 Combustion testing with large diameter liner

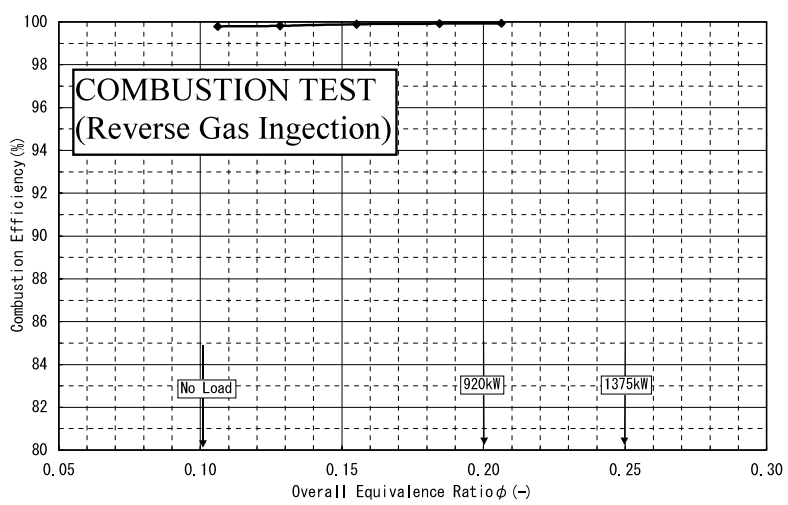

Fig. 17 Combustion efficiency of engine testing with large diameter liner

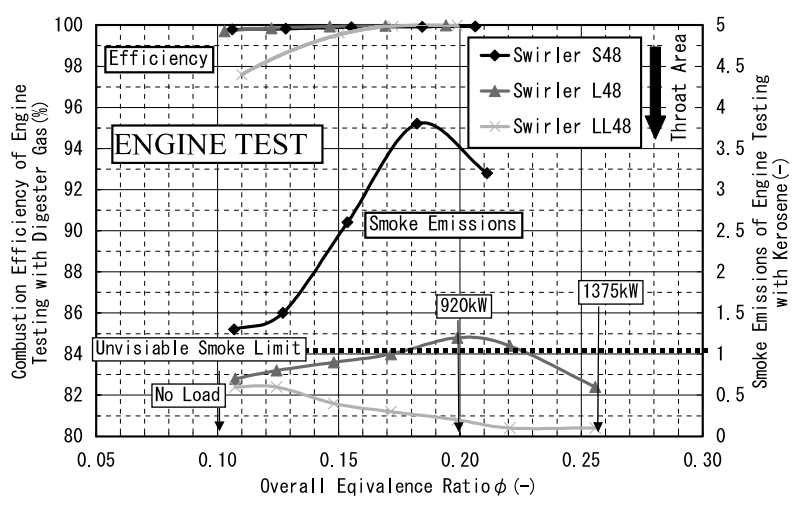

Fig. 18 Combustion efficiency and smoke emissions of digester gas and kerosene on engine test

large diameter liners, we obtained combustion efficiencies of at least $99.8 \%$ over the entire load range.

\subsection{Investigation of dual-fuel specifications}

The study achieved good combustion with digester gas. However, kerosene use in this combustor increased smoke emissions significantly, since the combustion equivalence ratio was increased to achieve good digester gas combustion. To reduce smoke emissions, we adjusted the combustion zone air flow rate by fineadjusting the swirlers within a range that avoids radical effects on digester gas combustion performance. The total open area was constant adjusting of dilution air hole 


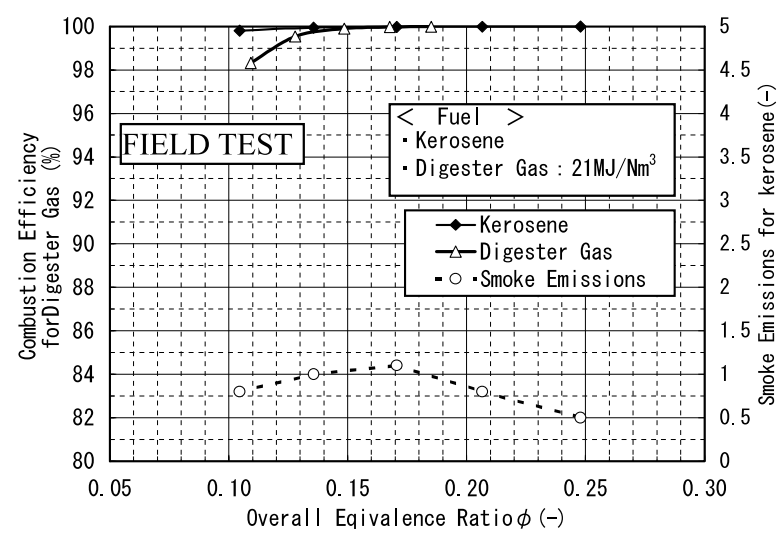

Fig. 19 Combustion efficiency and smoke emissions of field engine testing

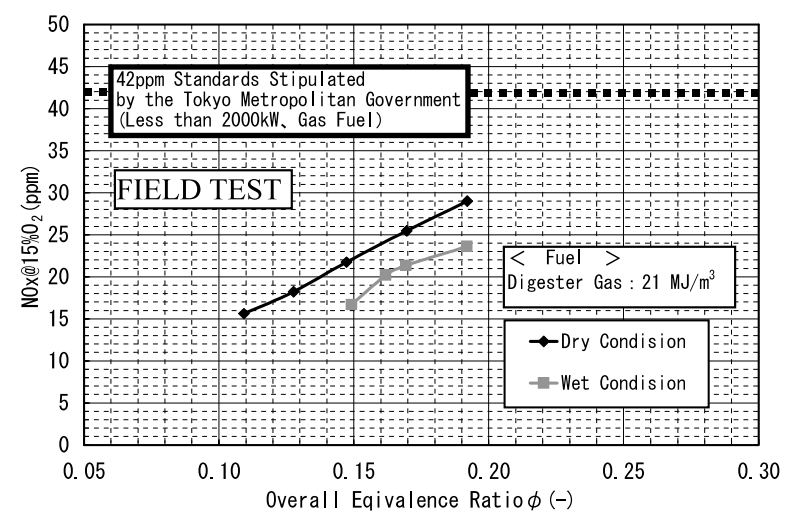

Fig. 20 NOx emissions with digester gas of field engine test

diameter. The results of this adjustment are shown in Fig. 18. Smoke emissions were extremely high when burning kerosene using the S48 swirler, which gave the best combustion efficiency for reverse swirl gas injection. Expanding the swirler throat area to LL48 size reduced smoke emissions below the target level. Nevertheless, a high combustion efficiency of digester gas was generally maintained exceeding $98 \%$ at low loads.

\section{Practical Application at Sewage Treatment Plants}

The combustor developed in this study is already installed in an emergency/continuous-use gas turbine generator at a sewage treatment plant in Tokyo. It has achieved satisfactory performance with sludge digester gas fuel in continuous operations and with kerosene in emergency operations. Figures 19 and 20 show combustion efficiencies and smoke and NOx emissions when burning kerosene as measured in situ.

Combustion efficiency is at least $98 \%$ when burning digester gas. With kerosene, we achieved high combustion efficiency throughout the operating range, with smoke emissions below the visible range. NOx emissions were below the $42 \mathrm{ppm}$ at $15 \% \mathrm{O}_{2}$ standards stipulated by the Tokyo Metropolitan Government. Water spraying further

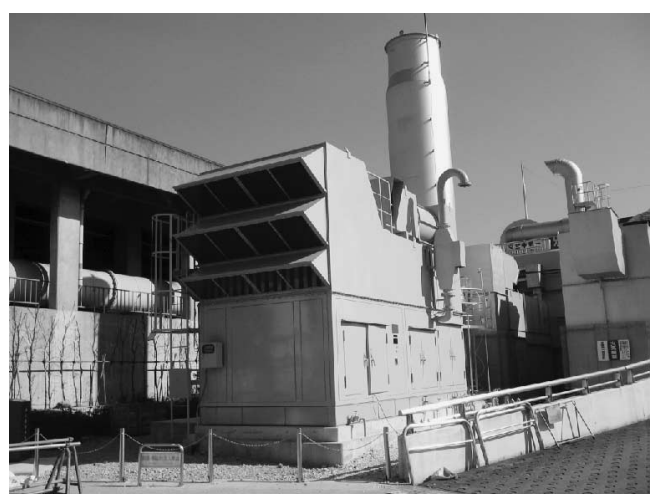

Fig. 21 Photo of the gas turbine engine

reduced NOx emissions. It has also been shown to provide satisfactory performance under wet conditions.

The combustor has operated reliably for one year. Figure 21 is a photo of the gas turbine engine.

\section{Summary}

This report describes the development of a gas turbine engine capable of burning either low-calorie gas and kerosene, which have significantly different combustion characteristics. The following two main points emerged during development:

(1) Imparting swirl to the fuel gas in the direction opposite of the air swirler promotes fuel-air mixing.

(2) Enlarging the conventional combustor diameter increases residence time in the combustor. In atmospheric pressure combustion tests, this increased combustion efficiency by approximately $3 \%$.

Conventional combustors have been studied using the same basic research and design methods applied to conventional gas turbine fuels, such as kerosene and natural gas. But the differences in flame stability with low-calorie gas argue against conventional combustion methods. It is our hope that the results obtained in this development study for low-calorie gas combustion can be applied to the combustion of other biomass fuels.

\section{Acknowledgements}

We are deeply indebted to the Basic Technology Research Laboratory at the Research Institute of Ishikawajima-Harima Heavy Industries Co., Ltd., for valuable advice during the course of this development study.

\section{References}

(1) Niigata Advances Combustion Technology, Diesel \& Gas Turbine Worldwide, June, (2004), pp.38-40.

(2) Sasaki, S., Trend of Emissions Regulation, GTSJ, Vol.23, No.89 (1995), pp.28-29.

( 3 ) Lefebvre, A.H., Gas Turbine Combustion, (1983), p.481, Taylor \& Francis. 